\title{
Esophageal perforation during endoscopic removal of food impaction in eosinophilic esophagitis: stent well spent?
}

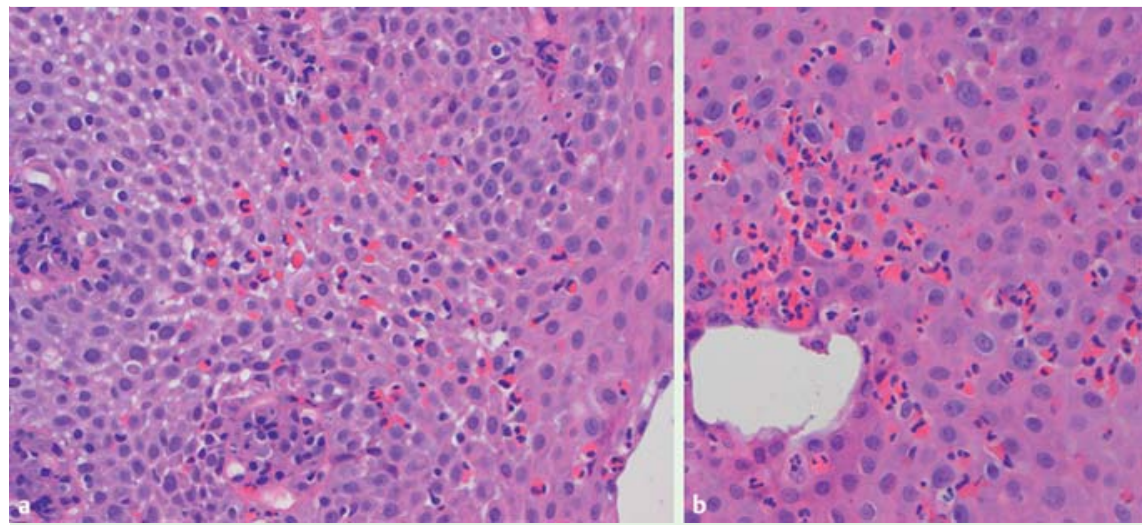

Fig. 1 Histology following hematoxylin and eosin staining. a Eosinophilic infiltration and spongiosis of the nonkeratinizing, stratified squamous epithelium. b Eosinophilic microabscesses.

A 31-year-old man with an allergic constitution who had previously undergone endoscopic removal of impacted food in 2008 was referred to the outpatient clinic for chronic intermittent dysphagia of solid food. An upper endoscopy performed after administration of high-dose proton pump inhibitors showed linear furrows. Examination of mid and proximal esophageal biopsy specimens showed mild basal hyperplasia, moderate spongiosis, and a peak of 120 intraepithelial eosinophils per high power field ( $\bullet$ Fig. 1 ). The patient was diagnosed with eosinophilic esophagitis [1]. The patient showed a partial response to swallowed fluticasone aerosol and subsequently to budesonide, and was referred to the outpatient clinic of our hospital.

Pending his appointment, the patient presented himself to the referring hospital with acute impaction of a piece of beef. Emergency endoscopy (performed without sedation) revealed an impacted food bolus in the distal esophagus ( Fig. 2 a). During the procedure the patient vomited violently, but the pressure failed to mobilize the food bolus. The bolus was removed using a snare and Roth Net retriever (US Endoscopy, Mentor, Ohio, USA). After bolus removal, the patient experienced pro- gressive epigastric pain, and a perforation was seen at $38 \mathrm{~cm}$ from the dental arcade ( $\bullet$ Fig.2b). A partially covered self-expandable metal Wallflex stent (diameter $18 \mathrm{~mm}$, length $100 \mathrm{~mm}, 70 \mathrm{~mm}$ covered; Boston Scientific, Natick, Massachusetts, USA) was placed and a double-lumen duodenal feeding probe was introduced. A chest radiograph demonstrated free mediastinal and upper abdominal air and the position of the stent in situ ( $\bullet$ Fig. 3 a). The patient received analgesics and antibiotics. An esophagogram performed 4 days after perforation showed no leakage of contrast, and the patient was discharged.

Stent removal was performed 3 weeks later at our hospital. The proximal esophagus demonstrated linear furrows and white exudates ( Fig. 2c). Unfortunately, stent removal was hindered by tissue ingrowth in the uncovered proximal part of the stent ( $\bullet$ Fig. $2 \mathrm{~d}$ ), and a fully covered Niti-S stent-in-stent was placed (diameter $18 \mathrm{~mm}$, length $60 \mathrm{~mm}$; Taewoong Medical, Seoul, Korea) ( Fig.3b). After 1 week, the Niti-S stent was easily removed $(\checkmark$ Fig. 2e); however, removal of the Wallflex stent required gentle back and forth manipulation ( $\bullet$ Fig.2f). The esophageal perforation had healed.
Eosinophilic esophagitis is often considered an innocent disease that causes only mild, discomforting symptoms [1]. The presented case reminds us that we should attempt to avoid food impaction in patients with eosinophilic esophagitis because endoscopic removal of the impacted food may cause perforation [2,3]. During endoscopy, preventative measures such as general anesthesia and the use of antiemetics may be required. In this patient, placement of a partially covered metal stent resulted in tissue ingrowth, which is a common complication of stent placement [4]. The placement of metal stents, especially partially covered ones, should be avoided in patients with eosinophilic esophagitis because the inflamed mucosa is likely to react to a foreign body by the development of severe fibrosis, and stent removal may also increase the risk of mucosal tears and perforation. Furthermore, endoscopists should be extra cautious when placing stents in patients with eosinophilic esophagitis who have esophageal rings, strictures, or a narrowcaliber esophagus, because the reduced esophageal luminal diameter may complicate stent removal.

\section{Endoscopy_UCTN_Code_CPL_1AH_2AD}

Competing interests: Dr. Bredenoord was supported by a grant from The Netherlands Organisation for Scientific Research (NWO). He has also received research funding from AstraZeneca, Endostim, MMS, Shire, and has received speaker fees from MMS and Shire.

Bram D. van Rhijn ${ }^{1}$, Wouter L. Curvers ${ }^{1}$, Jacques J. G. H. M. Bergman', Joanne Verheij'², Albert J. Bredenoord

${ }^{1}$ Department of Gastroenterology and Hepatology, Academic Medical Center, University of Amsterdam, Amsterdam, The Netherlands

${ }^{2}$ Department of Pathology, Academic Medical Center, University of Amsterdam, Amsterdam, The Netherlands 

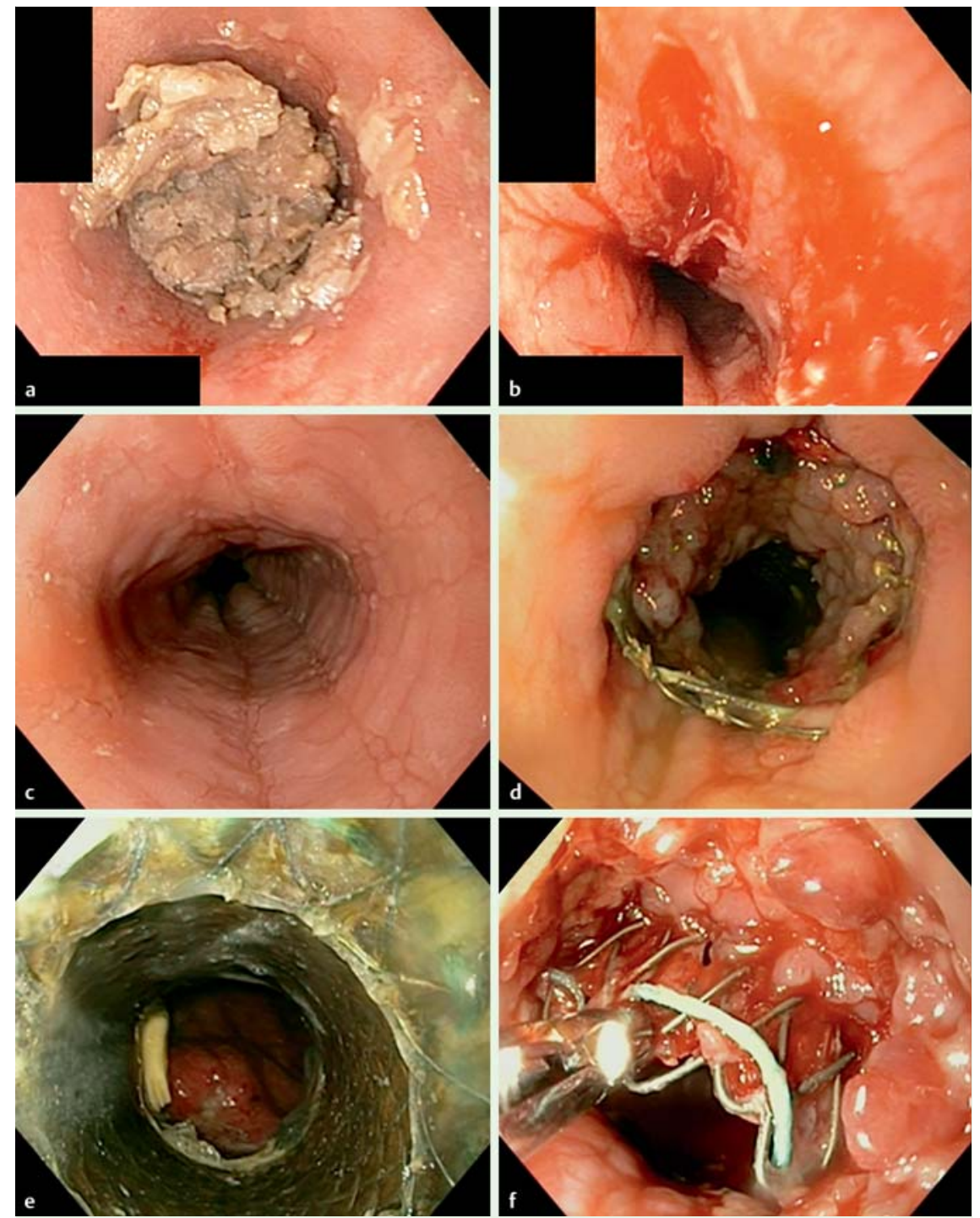

Fig. 2 Endoscopic procedures performed after food bolus impaction. a Impacted food bolus in the distal esophagus. $\mathbf{b}$ Esophageal perforation following the removal of the impacted food bolus. $\mathbf{c}$ Linear furrows and white exudates in the proximal esophagus. $\mathbf{d}$ Tissue ingrowth in the uncovered proximal section of the stent hindered its removal. e The stent-in-stent Niti-S stent was removed easily 1 week later. $\mathbf{f}$ Removal of the initial stent was eventually achieved by gentle back and forth manipulation.

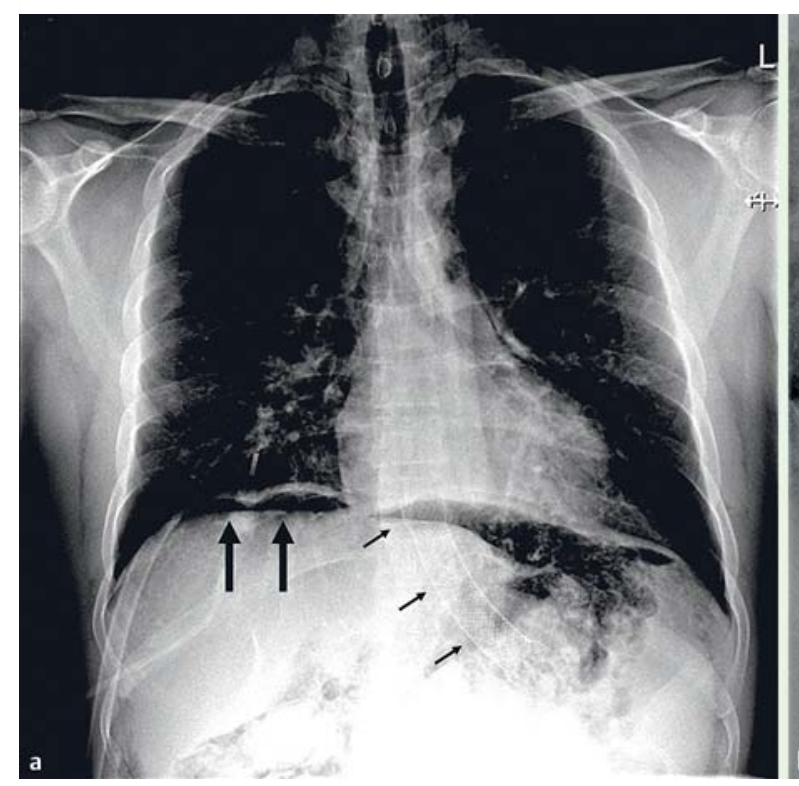

\section{References}

1 Liacouras CA, Furuta GT, Hirano I et al. Eosinophilic esophagitis: updated consensus recommendations for children and adults. J Allergy Clin Immunol 2011; 128: 3 - 20

2 Cohen MS, Kaufman AB, Palazzo JP et al. An audit of endoscopic complications in adult eosinophilic esophagitis. Clin Gastroenterol Hepatol 2007; 5: 1149-1153

3 Bohm ME, Richter JE. Review article: oesophageal dilation in adults with eosinophilic oesophagitis. Aliment Pharmacol Ther 2011; 33: $748-757$

4 Van Boeckel PG, Dua KS, Weusten BL et al. Fully covered self-expandable metal stents (SEMS), partially covered SEMS and self-expandable plastic stents for the treatment of benign esophageal ruptures and anastomotic leaks. BMC Gastroenterol 2012; 12: 19

\section{Bibliography}

DOI http://dx.doi.org/

10.1055/s-0034-1365150

Endoscopy 2014; 46: E193-E194

(c) Georg Thieme Verlag KG

Stuttgart · New York

ISSN 0013-726X

\section{Corresponding author}

\section{Bram D. van Rhijn, MD}

Department of Gastroenterology and Hepatology Academic Medical Center

Amsterdam

PO Box 22660

1100 DD Amsterdam

The Netherlands

Fax: +31-20-6917033

b.d.vanrhijn@amc.uva.n|
Fig. 3 Radiographic images. a Free upper abdominal air (large arrows) and the stent (small arrows) after perforation. $\mathbf{b}$ Niti-S stent positioned inside the proximal, uncovered part of the Wallflex stent. 